\title{
BMJ Open Comparative study of two birth cohorts: did the explanatory role of behavioural, social and psychological factors in educational inequalities in mortality change over time?
}

To cite: Klokgieters S, Kok A, Rijnhart J, et al. Comparative study of two birth cohorts: did the explanatory role of behavioural, social and psychological factors in educational inequalities in mortality change over time? BMJ Open 2022;12:e052204. doi:10.1136/ bmjopen-2021-052204

- Prepublication history and additional supplemental material for this paper are available online. To view these files, please visit the journal online (http://dx.doi.org/10.1136/ bmjopen-2021-052204).

Received 08 April 2021 Accepted 08 February 2022

D Check for updates

(c) Author(s) (or their employer(s)) 2022. Re-use permitted under CC BY-NC. No commercial re-use. See rights and permissions. Published by BMJ.

For numbered affiliations see end of article.

\section{Correspondence to}

Dr Silvia Klokgieters;

s.klokgieters@amsterdamumc. $\mathrm{nl}$

\section{ABSTRACT}

Objectives To investigate the contribution of behavioural, social and psychological factors to inequalities in mortality by educational level between birth cohorts.

Design Cohort-sequential design.

Setting Two population-based studies in the Netherlands: the Longitudinal Aging Study Amsterdam (LASA) and the Doetinchem Cohort Study (DCS).

Participants Data from the LASA included 1990 individuals with birth years 1928-1937 (cohort 1) and 1938-1947 (cohort 2) and, for replication, data from the DCS included 2732 individuals with birth years 1929-1941 (cohort 1) and 1939-1951 (cohort 2).

Methods Years of education, 15-year mortality, lifestyle factors, social factors and psychological factors were modelled using multiple-group accelerated failure time models based on structural equation modelling to compare indirect effects between cohorts.

Results Both studies showed similar educational inequalities, with higher mortality among those with lower education. The indirect effects of education via smoking (LASA: difference in survival time ratio (TR) $=1.0018,95 \% \mathrm{Cl}$ 1.0000 to 1.0155 , DCS: TR $=1.0051,95 \% \mathrm{Cl} 1.0000$ to 1.0183), physical activity (LASA: TR=1.0056, 95\% Cl 1.00009 to 1.0132 ) and alcohol use (LASA: TR $=1.0275,95 \% \mathrm{Cl}$ 1.0033 to 1.0194$)$ on mortality were stronger in cohort 2 than in cohort 1 . In contrast to the other effects, alcohol use was the only factor that was associated positively with education and survival time, which effect increased in the most recent cohort. Emotional support, network size and cognitive functioning showed no difference between cohorts. Conclusions Smoking, physical activity and alcohol use contributed more to educational inequalities in mortality in recent cohorts. Hence, in addition to tackling fundamental social causes of inequality, policies focusing on intermediary mechanisms such as lifestyle need to adapt their targets to those that prove to be most important within a given time frame.

\section{INTRODUCTION}

Throughout the 20th century, inequalities in mortality according to educational level
Strengths and limitations of this study

- Although educational inequalities in mortality is a widely studied topic in epidemiology and public health, this study is the first to investigate changes in the explanatory roles of behavioural, social and psychological factors across birth cohorts.

- The study uses data from two rich cohort studies based in the Netherlands and is therefore able to include a myriad of important behavioural social and psychological factors using the most recent insights from the causal mediation analysis framework.

- The cross-sectional design of this study limits our interpretation of the findings as reverse causality may explain the associations that were observed.

- The study largely relied on self-reported measures and may therefore be prone to recall bias or preferential reporting, which may partially explain changes over time.

- Because information on material factors was lacking, it is possible that the explanatory role of factors included in our study is slightly overestimated.

have been remarkably persistent across generations. $^{1-3}$ While overall mortality has declined in Western countries, declines were larger among individuals with higher education. ${ }^{45}$ Tackling educational inequalities in health and mortality seems not very successful yet and it is important to monitor educational inequalities in mortality and also the factors that explain them.

The Fundamental Cause Theory ${ }^{6}$ posits that factors explaining educational inequalities become replaced with others over time due to broad societal developments, which results in a persistence of educational inequalities in mortality. ${ }^{7}$ In this paper, we focus on several societal developments in the past decades, which suggest that explanatory 
factors of educational inequalities in mortality may have changed. ${ }^{8}$ First, knowledge about prevention and health behaviours has grown. ${ }^{1}$ For example, awareness of the negative health effects of smoking has increased policy attention to reduce smoking across Europe and the $\mathrm{USA}^{9}$ but may have reached people with higher education the most. As a consequence, smoking and hazardous drinking rates have dropped more strongly in higher than in lower educational groups. ${ }^{10}$ Accordingly, smoking and alcohol attributable mortality has decreased more among the higher educated. ${ }^{11}$

Second, processes of detraditionalisation and individualisation have increased divorce rates and changed family structures, all related to mortality. ${ }^{12}$ Divorce was more common among the higher educated, but this pattern has reversed during the latter decades of the 20th century. ${ }^{13}$ These societal processes also reduced the embeddedness of individuals in the neighbourhood community, church and family. ${ }^{14}$ Higher educated individuals tend to have larger social networks and to be more able to mobilise alternative sources of social support, such as non-kin, which may benefit health. ${ }^{15}$

Third, Western societies have provided more opportunities for upward mobility, presumably increasing the importance of personal talent and effort for life chances, referred to as 'meritocracy'. This development may increase the importance of cognitive ability and selfmanagement skills for educational and occupational success. ${ }^{1}$ Factors such as high sense of $\operatorname{control}^{16}$ and high cognitive functioning ${ }^{17}$ may have become concentrated among individuals with a higher education in later cohorts. These psychological characteristics also affect health, ${ }^{18-20}$ so they may have become more important for explaining educational inequalities in mortality.

Taken together, these developments may have changed the relative importance of known behavioural and psychosocial explanatory factors of educational inequalities in mortality, ${ }^{6}$ yet empirical evidence for this hypothesis is lacking. Cross-time comparisons will increase knowledge about the factors that are most important in explaining educational inequalities.

Therefore, the current study investigates changes in the explanatory role of behavioural, social and psychological factors in explaining educational inequalities in mortality between two birth cohorts in the Netherlands. Figure 1 visualises the theoretical model tested in this paper.

\section{METHODS \\ Data collection}

Data were derived from two population-based studies in the Netherlands: the Longitudinal Aging Study Amsterdam (LASA) ${ }^{21}$ and the Doetinchem Cohort Study (DCS). ${ }^{22}$

LASA is a longitudinal, multidisciplinary study, that captures physical, cognitive, social and emotional functioning. Respondents were randomly selected from the population registers of 11 urban and rural municipalities in Western, Southern and Northern regions. Respondents were visited at home by trained interviewers who conducted 2-hour interviews. Baseline data were collected in 1992-93 among adults and included 3107 respondents aged between 55 and 84 years (cooperation rate $=62 \%$ ). In 2002-2003, an additional cohort was included, which consisted of 1002 adults aged between 55 and 64 years (cooperation rate $=62 \%$ ). We included those ageing 55-64 years from both cohorts, 988 respondents from the baseline cohort (LASA-1) and 1002 from the second wave (LASA-2).

DCS is an ongoing longitudinal cohort study and focuses on the impact of lifestyle and biological risk factors on health. A sex-age-stratified sample of 20155 inhabitants of the Dutch town Doetinchem, in the East of the Netherlands, were invited. The first examination $(\mathrm{n}=12405$, response $=62 \%)$ took place in $1987-1991$, after which a random sample of 7768 persons aged between 20 and 59 years was reinvited for an examination every 5 years. As LASA provides the same independent age

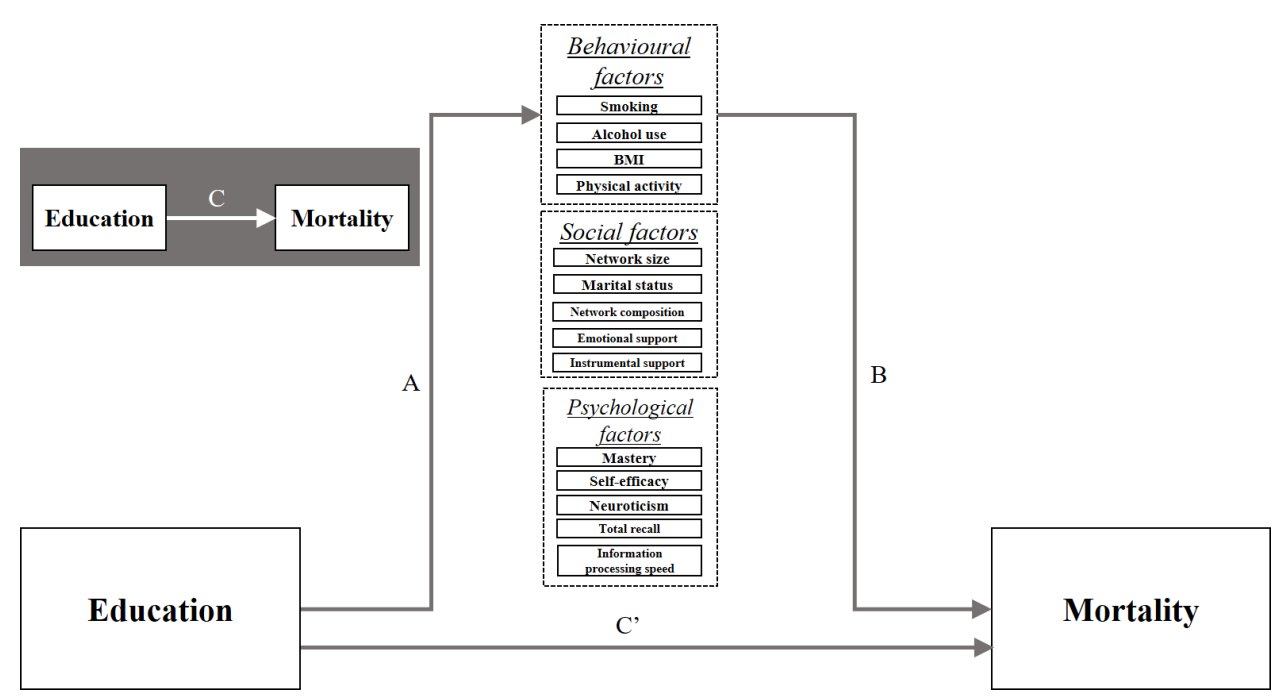

Figure 1 Visual presentation of second step in the analysis. 
groups observed one decennium apart, we selected a sample that matched the birth years and years of data collection as closely as possible. This resulted in a selection of respondents aged 55-64years from wave 2 (19931997, $\mathrm{n}=1352$, DCS-1) and from wave 4 (2003-2007, $\mathrm{n}=1380$, DCS-2).

\section{Patient and public involvement}

No patient was actively involved in the study.

\section{Outcome indicator}

15-year Mortality was retrieved from municipal registers. Registrations were completed up to 1 August 2018, for LASA, and up to 4 January 2020, for DCS.

\section{Socioeconomic indicator}

Education was obtained as the highest school level (nine levels). The levels were recoded into the nominal years.

\section{Explanatory factors}

A detailed description of all explanatory variables can be found in online supplemental table S1.

Smoking was assessed by asking respondents whether they had never smoked, ever smoked or smoked currently. This resulted in three categories: never smoker, former smoker and current smoker.

Alcohol use in LASA was derived from asking how many days in the week the respondents drink and how many drinks they consume each time. In DCS respondents were asked about their weekly consumption of alcoholic beverages. The questions were recoded to average weekly alcohol consumption: abstainer, 5 glasses a week or less and more than 5 glasses a week. ${ }^{23}$

Body mass index was calculated by dividing measured body weight in kilograms by measured height in metres squared.

For LASA, physical activity was based on the LASA Physical Activity Questionnaire, and for DCS on the European Prospective Investigation into Cancer and Nutrition (EPIC) physical activity questionnaire. ${ }^{24}$ We selected activities that were present in both studies, which included walking outdoors, bicycling, gardening, household activities and two sports and recreational activities. A sum score was created by multiplying the minutes spent per activity per day by the metabolic equivalent of task scores. ${ }^{25}$ Due to non-normality of residuals, physical activity was $\log$ transformed.

Divorce was based on a question asking about the current marital status.

For episodic memory, we used the immediate and delayed recall of the 15-words test.

Information processing speed (IPS) was based on a coding task during which respondents named as many correct characters as possible out of several character combinations; verbally for LASA and written for DCS. This was done in three cycles of $1 \mathrm{~min}$. The average of the three trials was used.

\section{The following variables were available only in LASA:}

Mastery reflects an individual's perception of having personal control over one's life in general, measured with the five-item Pearlin Mastery Scale. ${ }^{26}$

Self-efficacy assessed an individual's belief in their ability to organise and execute behaviours that are necessary in order to attain personal goals, measured with 12-item General Self-Efficacy Scale. ${ }^{27}$

Neuroticism reflects an individual's proneness to psychological distress, measured with 15 items from the Dutch Personality Questionnaire. ${ }^{28}$

Network size included the number of frequent and important contacts older than 17 years.

Network complexity assessed the number of social roles a respondent has regular contact with. ${ }^{29}$ There were 13 possible social roles: Spouse, child, child-in-law, sibling, sibling-in-law, parent, (other) relative, close friend, acquaintance, neighbour, (former) colleague, voluntary organisation and other group.

Emotional and instrumental support were based on the nine network members indicated as most important by the participant.

Emotional support indicated the frequency of talking about personal experiences and feelings with these network members.

Instrumental support indicated the frequency of receiving help with daily chores around the house.

\section{Data analyses}

Differences in characteristics between cohorts are determined using $\chi^{2}$ tests for categorical variables and t-test statistics for interval variables. We conducted mediation analyses with single-mediator and multiple-mediator models for each cohort using multiple-group generalised structural equation models in STATA V.16. The total effect of education on mortality was estimated using accelerated failure time (AFT) models ( $c$ path in figure 1) to ensure a causal interpretation, as the outcome was not rare (prevalence $>10 \%) .{ }^{30}$ Based on the Akaike Information Criterion, which we compared across models assuming different distributions, Weibull error distribution was chosen and used in subsequent models. The effects of education on the mediators ( $a$ paths) were estimated using multinomial logistic regression for categorical mediators (smoking, alcohol use, divorce) and linear regression for continuous mediators (all other mediators). The direct effect of education on mortality ( $c$ ' paths), and the effects of the mediators on mortality ( $b$ paths), were estimated using AFT models. Indirect effects reflect the effects of education on mortality through specific mediators and were estimated using the product-of-coefficients method. ${ }^{31}$ In order to account for scale differences, the $a$ paths were transformed to a risk difference scale. ${ }^{32} 95 \%$ CIs around the indirect effects were calculated using 1000 bootstrap resamples. $^{33}$

To examine whether the strength of the indirect effect differed between cohorts, we tested for equality of indirect effect estimates with a Wald test (henceforward indicated by 
the difference in natural logarithm survival time ratio (TR)). If the strength of an indirect effect estimate was larger in the later cohort, we assumed that explanatory role of the mediator became more important over time. To investigate if cohort differences were induced by differences in the $a$, the $b$, or both paths, we additionally tested the equality of specific path coefficients with a Wald test.

Parallel multiple mediator models were estimated in order to determine the relative magnitudes of the specific indirect effects associated with all mediators mutually adjusted. For each study all mediators for which the indirect effect estimates were that statistically significant in at least one cohort were estimated, using the same procedures as described above.

Age and sex were used as control variables in all models and were grand-mean centred. Missing data were handled with equationwise deletion. All analyses were performed separately for LASA and DCS. The significance level was set at $5 \%$.

\section{RESULTS}

\section{Descriptive statistics}

Descriptive statistics for both cohorts of LASA and both cohorts of DCS are depicted in table 1. The average years of education was higher, and the prevalence of 15-year mortality lower in the second cohort in both studies. The percentage of people who divorced, the percentage of people who drank more than five glasses a week, and the average cognitive ability were higher in both second cohorts.

\section{Total effect of education on mortality}

Table 2 presents the total effect estimates ( $c$ paths) derived from the AFT models, which represent the survival TR per additional year of education for each cohort separately. The estimates confirmed that individuals with more years of education had a longer average survival time than individuals with less years of education. In both studies, the effects of education were statistically significant in the second cohort only. In DCS, the effects differed significantly between cohorts and indicated larger educational inequalities in DCS-2 compared with DCS-1.

\section{Cohort differences in explanatory factors in the LASA}

Table 3 depicts the indirect effect estimates of education on mortality through behavioural, social and psychological factors, for LASA. The indirect effect through a mediator indicates whether a 1-year increase in the years of education on average results in a longer or shorter survival time through an increase in the mediator.

We found that three indirect effect estimates differed significantly between cohorts. First, the indirect effect of education on mortality through former smoking was larger in LASA-2 than in LASA-1 (TR $=1.0018,95 \%$ CI 1.0000 to 1.0156 ; table 3). However, neither the a-path nor the b-path changed significantly between the cohorts. Therefore, the change in the indirect effect was due to slight changes in both the $a$ and $b$ paths. The effect of education on former smoking changed from positive to negative, and the effect of former smoking and survival time increased (online supplemental table S2a).

Second, the indirect effect of education on mortality through drinking more than five glasses a week became positive in LASA-2 compared with LASA-1 (TR=1.0279, 95\% CI 1.0033 to 1.0612 ; table 3 ). This change was due to a longer survival time for individuals who drink more than five glasses a week in the second cohort (b-paths; online supplemental table S2a).

Third, the indirect effect from education on mortality through physical activity was larger in LASA-2 than in LASA-1 (TR=1.0056, 95\% CI 1.0009 to 1.0133 ; table 3). This was due to both a larger positive effect between physical activity and survival time (b-path online supplemental table S2a).

\section{Differences in explanatory factors in the DCS}

The indirect effect from education to mortality through current smoking was stronger in DCS-2 compared with DCS-1 (TR=1.00511, 95\% CI 1.00000 to 1.01847 ) (table 4). This was due to a stronger negative effect between current smoking and survival time (online supplemental table S2b).

\section{Multiple mediator model}

For LASA, the multiple mediator model included smoking, alcohol use, physical activity, network size, emotional support, episodic memory and IPS. For DCS, the multiple mediator model included smoking, alcohol use, marital status, episodic memory and IPS (depicted in online supplemental figure S1a,b). For LASA, the indirect effect through smoking and for DCS the indirect effects via alcohol use and IPS remained statistically significant after inclusion of other mediators. Although the total indirect effect increased for both studies, this change was not statistically significant. This suggests that the overall contribution of these sets of mediators to educational inequalities in mortality was about equal between birth cohorts (see online supplemental table S3a,b).

\section{DISCUSSION}

In this study, we examined differences in explanatory factors of educational inequalities in mortality between two cohorts, born in the 1930s and the 1940s, in two population-based studies in the Netherlands (LASA and DCS). Relative educational inequalities in mortality were stable in LASA, and larger in the later cohort in DCS. Differences in indirect effect estimates between cohorts suggest that the explanatory role of smoking (LASA and DCS) and the explanatory roles of alcohol use and physical activity (LASA only) became more important. The importance of social network size, emotional support received and cognitive functioning did not differ between generations. 
Table 1 Characteristics of 55-64 year olds from different birth cohorts derived from Longitudinal Aging Study Amsterdam (LASA) and Doetinchem Cohort Study (DCS)

\begin{tabular}{|c|c|c|c|c|c|c|c|c|}
\hline & \multirow[b]{2}{*}{$\mathbf{N}$} & \multirow{2}{*}{$\begin{array}{l}\text { LASA-1 } \\
\begin{array}{l}\text { Mean(SD)/N } \\
(\%)\end{array}\end{array}$} & \multirow{2}{*}{$\begin{array}{l}\text { LASA-2 } \\
\begin{array}{l}\text { Mean(SD)/N } \\
(\%)\end{array}\end{array}$} & \multirow{2}{*}{$\begin{array}{l}P \text { value } \\
\text { t/F test }\end{array}$} & \multirow[b]{2}{*}{$\mathbf{N}$} & \multirow{2}{*}{$\begin{array}{l}\text { DCS-1 } \\
\text { Mean } \\
\text { (SD)/N (\%) }\end{array}$} & \multirow{2}{*}{$\begin{array}{l}\text { DCS-2 } \\
\begin{array}{l}\text { Mean (SD)/N } \\
(\%)\end{array}\end{array}$} & \multirow{2}{*}{$\begin{array}{l}\text { P value } \\
\text { t/F test }\end{array}$} \\
\hline & & & & & & & & \\
\hline \multicolumn{9}{|l|}{$\operatorname{Sex}(0-1)$} \\
\hline Women & 1990 & $516(52)$ & $527(53)$ & & 2723 & $707(50)$ & $701(50)$ & \\
\hline \multicolumn{9}{|l|}{ Behavioural factors } \\
\hline Smoking (0-2) & & & & & & & & $<0.05$ \\
\hline Never smoker & 452 & $236(24)$ & $216(24)$ & & 906 & $444(33)$ & $462(34)$ & \\
\hline Former smoker & 806 & $381(39)$ & $425(46)$ & & 1230 & $583(44)$ & $647(47)$ & \\
\hline Less than 5 glasses a week & 506 & $268(30)$ & $239(26)$ & & 432 & $245(19)$ & $178(13)$ & \\
\hline More than 5 glasses a week & 1088 & $483(54)$ & $605(66)$ & & 1354 & $561(42)$ & $793(58)$ & \\
\hline Physical activity score ${ }^{*} \dagger$ & 1939 & $46.7(41.3)$ & $38.8(39.2)$ & $<0.001$ & 2722 & $81.3(91.1)$ & $78.0(63.5)$ & $<0.001$ \\
\hline BMI (19-45) & 1782 & $26.7(3.7)$ & $27.4(4.3)$ & $<0.01$ & 2717 & $27.1(3.8)$ & $27.1(4.0)$ & \\
\hline \multicolumn{9}{|l|}{ Social factors } \\
\hline Divorced (0-2) & & & & $<0.01$ & & & & $<0.01$ \\
\hline Widowed or never partnered & 1830 & $152(15)$ & $110(11)$ & & 242 & $140(14)$ & $102(7)$ & \\
\hline Divorced & 168 & $57(6)$ & $111(11)$ & & 177 & $61(6)$ & $116(8)$ & \\
\hline Married & 1560 & $779(79)$ & $781(88)$ & & 1994 & $837(81)$ & $1157(84)$ & \\
\hline Total recall & 1797 & $21.5(5.6)$ & $20.6(5.5)$ & $<0.01$ & 2723 & $19.3(6.8)$ & $22.1(7.2)$ & $<0.05$ \\
\hline Mastery (8-25) & 1958 & $17.9(3.3)$ & $18.1(3.4)$ & & & & & \\
\hline Self-efficacy (23-59) & 1961 & $42.9(5.2)$ & $43.4(5.6)$ & & & & & \\
\hline Neuroticism (0-28) & 1721 & $5.7(4.8)$ & $5.4(4.8)$ & & & & & \\
\hline
\end{tabular}

*Due to non-normality median, an IQR is reported.

†Range varies from 0-371 in LASA and 0-391 in DCS.

$\mathrm{BMI}$, body mass index.

The different changes in the indirect effects via smoking between LASA and DCS appear contradictory at first sight. However, we believe that both capture the same phenomenon. In both cases, we find that in the later cohort, higher educated individuals were less likely to smoke than in the earlier cohort. This finding is in line with the theory of diffusion of innovations, which argues that smoking was first taken up by individuals with a higher education, and later this 'innovation' diffused to individuals with a lower education. ${ }^{10}$ The data from
LASA seem to illustrate this transition, where smoking was more common among higher educated individuals in the earlier cohort but was increasingly taken up by lower educated individuals in the later cohort. The data from DCS suggest that this sample had progressed further; in the earlier cohort of DCS, smoking was already more common in the low educated, and this remained the same in the later cohort. We thus find evidence for the increasing importance of smoking for educational inequalities in mortality. 
Table 2 Total effect estimates expressed in terms of survival time ratio for education in years separately for each cohort in LASA and DCS (C)

\begin{tabular}{lllll}
\hline & STR & \multicolumn{1}{l}{$95 \%$ Cl } & STR & $\mathbf{9 5 \%}$ Cl \\
\hline Education & LASA-1 & & LASA-2 \\
& 1.030 & 0.998 to 1.064 & 1.063 & 1.023 to 1.104 \\
& DCS-1 & & DCS-2 & \\
$1.023^{*}$ & 0.999 to 1.049 & $1.062 \dagger$ & 1.026 to 1.097
\end{tabular}

*Different from LASA-2 or DCS-2.

†Different from LASA-1 or DCS-1.

STR, survival time ratio, which is calculated $\exp (\mathrm{B})$.

In LASA, we found an increase in the explanatory role of drinking more than five glasses a week between cohorts. It appears that highly educated individuals were more likely to drink more than five glasses a week and this unexpectedly was associated with a longer survival time. One explanation may be residual confounding. Drinking more than five glasses a week was most common among higher educated individuals, who on average possess more resources such as a larger network size or higher sense of control over one's on life. ${ }^{16}$ In addition, drinking alcohol, in specific social groups or contexts, has been associated with social advantages, such as reducing social anxiety. ${ }^{34}$ It may be that among generations and social groups in which alcohol use is high and the opinion is positive, the social benefits of drinking alcohol outweigh the negative consequences. ${ }^{35}$ This possibility is supported by our finding that the indirect effect via drinking was not statistically significant anymore after adjustment for other mediators, including network size and emotional support.

The explanatory role of physical activity for educational inequalities in mortality increased between cohorts in LASA. This was due to increasing positive effects of physical activity on survival. These findings suggest that the negative association between education and mortality regularly found in previous studies, ${ }^{36}$ may be changing over time. An increased importance of lifestyle attributed diseases, as a consequence of the epidemiological transition, ${ }^{1}$ may explain physical activity's increased importance for mortality.

Table 3 Indirect effects of education on mortality through the mediators between cohorts (LASA)

\begin{tabular}{|c|c|c|c|c|c|c|}
\hline \multirow[b]{2}{*}{ Behavioural factors } & \multicolumn{2}{|l|}{ LASA-1 } & \multicolumn{2}{|l|}{ LASA-2 } & \multicolumn{2}{|c|}{$\begin{array}{l}\text { Difference in LN survival } \\
\text { time ratio (TR) }\end{array}$} \\
\hline & STR/B & $95 \% \mathrm{Cl}$ & STR/B & $95 \% \mathrm{Cl}$ & STR/B & $95 \% \mathrm{Cl}$ \\
\hline \multicolumn{7}{|l|}{ Through smoking } \\
\hline Through former smoking & 0.9983 & 0.9880 to 1.0000 & 1.0000 & 0.9994 to 1.0025 & 1.0018 & 1.0000 to 1.0156 \\
\hline Through current smoking & 0.9998 & 0.9874 to 1.0009 & 1.0004 & 1.0000 to 1.0124 & 1.0008 & 0.9965 to 1.0090 \\
\hline Through alcohol & 0.9993 & 0.9977 to 1.0002 & 1.0003 & 0.9997 to 1.0012 & 1.0010 & 0.9999 to 1.0026 \\
\hline through $<5$ glasses & 1.0012 & 0.9923 to 1.0139 & 1.0190 & 0.9995 to 1.0540 & 1.0178 & 0.9949 to 1.0543 \\
\hline through $>5$ glasses & 0.9946 & 0.9781 to 1.0074 & 1.0223 & 1.0038 to 1.0555 & 1.0279 & 1.0033 to 1.0612 \\
\hline Through physical activity & 1.0004 & 0.9995 to 1.0036 & 1.0060 & 1.0017 to 1.0136 & 1.0056 & 1.0009 to 1.0133 \\
\hline Through BMI & 0.9996 & 0.9933 to 1.0054 & 1.0001 & 0.9938 to 1.0064 & 1.0004 & 0.9908 to 1.0081 \\
\hline \multicolumn{7}{|l|}{ Social factors } \\
\hline \multicolumn{7}{|l|}{ Through marital status } \\
\hline Through divorce & 0.9997 & 0.9988 to 1.0005 & 0.9988 & 0.9975 to 1.0025 & 0.9992 & 0.9973 to 1.0026 \\
\hline Through married & 1.0013 & 0.9983 to 1.0078 & 0.9988 & 0.9975 to 1.0001 & 0.9975 & 0.9907 to 1.0010 \\
\hline Through network size & 1.0033 & 0.9986 to 1.0091 & 1.0082 & 1.0023 to 1.0185 & 0.9950 & 0.9847 to 1.0028 \\
\hline Through network complexity & 0.9995 & 0.9959 to 1.0017 & 1.0004 & 0.9978 to 1.0043 & 0.9991 & 0.9944 to 1.0027 \\
\hline Through instrumental support & 1.0000 & 0.9985 to 1.0011 & 1.0000 & 0.9982 to 1.0017 & 1.0000 & 0.9978 to 1.0020 \\
\hline Through emotional support & 1.0040 & 1.0009 to 1.0105 & 1.0041 & 0.9971 to 1.0118 & 1.0001 & 0.9918 to 1.0090 \\
\hline \multicolumn{7}{|l|}{ Psychological factors } \\
\hline $\begin{array}{l}\text { Through information processing } \\
\text { speed }\end{array}$ & 1.0245 & 1.0083 to 1.0420 & 1.0064 & 0.991 to 1.0229 & 1.0180 & 0.9954 to 1.0420 \\
\hline Through episodic memory & 1.0121 & 1.0021 to 1.0235 & 1.0051 & 0.9916 to 1.0198 & 0.9931 & 0.9771 to 1.0094 \\
\hline Through mastery & 0.9998 & 0.9977 to 1.0018 & 1.0003 & 0.9950 to 1.0056 & 1.0006 & 0.9936 to 1.0050 \\
\hline Through self-efficacy & 0.9991 & 0.9923 to 1.0058 & 1.0022 & 0.9940 to 1.0112 & 1.0031 & 0.9857 to 1.0074 \\
\hline Through neuroticism & 1.0035 & 0.9940 to 1.0102 & 1.0037 & 0.9981 to 1.0098 & 1.0002 & 0.9926 to 1.0014 \\
\hline
\end{tabular}

STR, survival time ratio, which is calculated $\exp (\mathrm{B})$, adjusted for age and sex.

BMI, body mass index. 
Table 4 Indirect effects of education on mortality through the mediators in the total sample and across cohorts (DCS)

\begin{tabular}{|c|c|c|c|c|c|c|}
\hline \multirow[b]{2}{*}{ Behavioural factors } & \multicolumn{2}{|l|}{ DCS-1 } & \multicolumn{2}{|l|}{ DCS-2 } & \multicolumn{2}{|c|}{ Difference in LN survival TR } \\
\hline & STR & $95 \% \mathrm{Cl}$ & STR & $95 \% \mathrm{Cl}$ & STR & $95 \% \mathrm{Cl}$ \\
\hline \multicolumn{7}{|l|}{ Through smoking } \\
\hline Through current smoking & 1.00010 & 1.00000 to 1.00351 & 1.00521 & 1.00020 to 1.01857 & 1.00511 & 1.00000 to 1.01847 \\
\hline$<5$ glasses a week & 1.00280 & 1.00010 to 1.01400 & 0.99900 & 0.98758 to 1.00130 & 0.99611 & 0.98295 to 1.00040 \\
\hline Through physical activity & 1.00020 & 0.9996 to 1.00160 & 1.00010 & 0.99900 to 1.00160 & 1.00000 & 0.99840 to 1.00160 \\
\hline Through BMI & 1.00220 & 0.9982 to 1.00602 & 0.99950 & 0.99332 to 1.00511 & 0.99730 & 0.99611 to 1.01056 \\
\hline \multicolumn{7}{|l|}{ Social factors } \\
\hline \multicolumn{7}{|l|}{ Through marital status } \\
\hline $\begin{array}{l}\text { Through information } \\
\text { processing speed }\end{array}$ & 1.02963 & 1.01969 to 1.04331 & 1.01511 & 1.00501 to 1.02737 & 0.98590 & 0.97132 to 1.00060 \\
\hline Through episodic memory & 1.02388 & 1.01501 to 1.03087 & 1.03541 & 1.00260 to 1.05138 & 1.01116 & 0.97239 to 1.00632 \\
\hline
\end{tabular}

STR, survival time ratio, which is calculated $\exp (\mathrm{B})$, adjusted for age and sex.

BMI, body mass index.

Although most changes in explanatory factors of educational inequalities in mortality were in the same direction in the two included studies, the differences in findings warrant further clarification. One explanation may be that the LASA cohort was recruited slightly earlier than the DCS cohort (LASA-1: 1992-1993, LASA-2: 2002-2003, DCS-1: 1993-1997, DCS: 2003-2007). Therefore, developments with regards to the changes in explanatory factors, might be slightly ahead in DCS compared with LASA. Another explanation might be that the studies cover regions with different levels of urbanicity, income, religiousness and religious denomination ${ }^{37-39}$ (for specific informationsee online supplemental table S4 and figure S2). Cultural and social differences between regions are known to influence the progression of modernisation and as such affect tolerance towards divorce, social network structures ${ }^{40}$ and potentially also attitudes towards health behaviours. Future studies examining cross-regional and cross-national differences may be needed to clarify these issues.

\section{Strengths and limitations}

We conducted analyses using recent insights from the mediation literature in two large studies that included multiple cohorts as well as a broad range of explanatory variables, which can be considered a strength of our study. Although many causes of health inequalities have been identified in particular periods, we consider testing cohort differences in explanatory factors of socioeconomic inequalities in health to be an important step in understanding the persistence of health inequalities that have been considered paradoxical by scientists and policy makers in recent years. ${ }^{141}$

Five limitations need to be mentioned. First, we relied on self-reported measures of health behaviours, social network properties and psychological characteristics. Recall bias and preferential reporting may have occurred. Insofar as the social acceptability of certain behaviours vary across educational groups between cohorts, it may have affected our results. Second, there were differences in the way questions were asked between the studies, particularly for physical activity, for which the activities included slightly differed between studies. These variations, may have been partly responsible for differences in findings between the two included studies. Third, comparing effect estimates derived from models using a non-linear link function, as we have done by comparing the effect sizes of mediators between cohorts, have to be interpreted with caution due to comparability issues resulting from non-collapsability. To date, there are no simple all-purpose solutions to the problems of interpretability and comparison of effect estimates. ${ }^{42}$ As such, we have employed criteria such as statistical significance testing between cohorts and within cohorts to enhance the reliability of our findings. Fourth, compared with the general population, lower educated individuals are slightly over-represented in DCS, while the educational categories in LASA were fairly representative of the general population. Fifth, neither DCS nor LASA had information about material factors, such as living and housing conditions, which are considered to play an important explanatory role in educational inequalities in 
health. ${ }^{43}$ Moreover, it is possible that there may be other sources of unmeasured confounding. Therefore, it is possible the explanatory role of factors included in this study is slightly overestimated.

\section{CONCLUSION}

In conclusion, we found evidence that explanatory mechanisms of educational mortality inequalities tend to change across birth cohorts. Specifically, we found that smoking became a more important explanatory factor in the most recent birth cohort, and this was found in both studies. Other factors that became more important were alcohol use and physical activity-although evidence to support this was found in only one of the included studies. Most psychosocial factors remained equally important across cohorts. Hence, mechanisms explaining educational inequalities in mortality are not fixed over time. Our results suggest that researchers and policy-makers need to monitor explanatory mechanisms and consider how (features of) contemporary societies may reshape these mechanisms. Proper contextualisation of policies is needed in order to keep up with mechanisms that change over time. Based on our findings, we recommend that policy efforts, in addition to tacking fundamental causes of inequality such as poverty, focus on strategies to improve the lifestyle as well as psychosocial resources of individuals with a lower education in order to reduce educational inequalities in health.

\section{Author affiliations}

'Deparment of Epidemiology and Data Science, Amsterdam Public Health Research Institute, Amsterdam UMC - location VU University Medical Center, Amsterdam, The Netherlands

${ }^{2}$ Department of Psychiatry, Amsterdam Public Health, Amsterdam University Medical Center, Vrije Universiteit, Amsterdam, The Netherlands

${ }^{3}$ Department of Health Sciences, Faculty of Science and Amsterdam Public Health research institute, Vrije Universiteit, Amsterdam, The Netherlands

${ }^{4}$ Department of Sociology, Faculty of Social Sciences, Vrije Universiteit, Amsterdam, Noord-Holland, The Netherlands

${ }^{5}$ Julius Center for Health Sciences and Primary Care, University Medical Center Utrecht, Amsterdam, The Netherlands

${ }^{6}$ Centre for Nutrition, Prevention and Health Services, National Institute for Public Health and the Environment, Bilthoven, The Netherlands

Contributors AK and MH conceived the study. SK performed the analyses and JR reviewed the analysis. SK wrote the manuscript. AK, MH, JR and SP contributed to the interpretation of the results in early and successive stages of the analyses. AK, MH, SP, MV, MVerschuren and MVisser critically revised the manuscript. All authors contributed to the interpretation of the results, approved the final manuscript, and agreed to be accountable for all aspects of the work. MH and SP are guarantors of this work.

Funding This work was supported by the Netherlands Organization for Health Research and Development (ZonMw) [grant number 50-53100-98-308] (https:// www.zonmw.nl/nl/). The Longitudinal Aging Study Amsterdam is supported by a grant from the Netherlands Ministry of Health Welfare and Sports, Directorate of Long-Term Care (https://www.government.nl/ministries/ministry-ofhealth-welfareand-sport) [grand number N/A]. The data collection in 2012-2013 and 2013-2014 was financially supported by the Netherlands Organization for Scientific Research (NWO) in the framework of the project "New Cohorts of young old in the 21st century" [grand number 480-10-014] (https://www.nwo.nl/).

Competing interests None declared.

Patient consent for publication Not applicable.
Ethics approval The study was conducted according to the principles of the World Medical Association Declaration of Helsinki and its amendments since 1964, and in accordance with the Medical Research Involving Human Subject Act (WMO). LASA was approved by the Medical Ethical Committee of the Vrije Universiteit Medical Center in Amsterdam, the Netherlands. DCS was approved by the Medical Ethical Committee (Medisch Ethische Commissie) of the Netherlands Organization of Applied Science Research (rounds 2 and 3), respectively, the Medical Ethical Committee (Medisch-Ethische Toetsingscommissie) of University Medical Center Utrecht (rounds 4 and 7). All participants gave written informed consent (ID: N/A) Participants gave informed consent to participate in the study before taking part.

Provenance and peer review Not commissioned; externally peer reviewed.

Data availability statement Data are available upon reasonable request. Access to data from the Longitudinal Aging Study Amsterdam can be requested by submitting a LASA analysis proposal form for evaluation. The LASA evaluation committee provides access to the data on the condition that the goals of the data request are in keeping with the overarching aims of LASA that its participants have provided consent for. The LASA analysis proposal template includes the option to request data for replication purposes. The template of the analysis proposal form can be obtained at www.lasa-vu.nl, or by sending a request to the LASA secretariat, f.kursun@amsterdamumc.nl. Analysis proposals can be submitted to the LASA secretariat. The data of the Doetinchem Cohort Study cannot be placed in a public repository due to legal and ethical constraints. The participants' informed consent did not include consent to public availability of the data. However, the data are available upon request, by contacting the scientific committee of the Doetinchem Cohort Study by email: Doetinchemstudie@rivm.nl.

Supplemental material This content has been supplied by the author(s). It has not been vetted by BMJ Publishing Group Limited (BMJ) and may not have been peer-reviewed. Any opinions or recommendations discussed are solely those of the author(s) and are not endorsed by BMJ. BMJ disclaims all liability and responsibility arising from any reliance placed on the content. Where the content includes any translated material, BMJ does not warrant the accuracy and reliability of the translations (including but not limited to local regulations, clinical guidelines, terminology, drug names and drug dosages), and is not responsible for any error and/or omissions arising from translation and adaptation or otherwise.

Open access This is an open access article distributed in accordance with the Creative Commons Attribution Non Commercial (CC BY-NC 4.0) license, which permits others to distribute, remix, adapt, build upon this work non-commercially, and license their derivative works on different terms, provided the original work is properly cited, appropriate credit is given, any changes made indicated, and the use is non-commercial. See: http://creativecommons.org/licenses/by-nc/4.0/.

\section{ORCID iDs}

Silvia Klokgieters http://orcid.org/0000-0002-9229-1778

Almar Kok http://orcid.org/0000-0001-6398-2484

Judith Rijnhart http://orcid.org/0000-0002-1046-3741

Marjolein Visser http://orcid.org/0000-0002-5136-298X

Marjolein Broese van Groenou http://orcid.org/0000-0002-9764-0092

Monique Verschuren http://orcid.org/0000-0003-2134-4227

Susan Picavet http://orcid.org/0000-0002-6895-165X

Martijn Huisman http://orcid.org/0000-0002-8851-9629

\section{REFERENCES}

1 Mackenbach JP. The persistence of health inequalities in modern welfare states: the explanation of a paradox. Soc Sci Med 2012;75:761-9.

2 Lynch SM. Explaining life course and cohort variation in the relationship between education and health: the role of income. $J$ Health Soc Behav 2006;47:324-38.

3 Masters RK, Link BG, Phelan JC. Trends in education gradients of 'preventable' mortality: a test of fundamental cause theory. Soc Sci Med 2015;127:19-28.

4 Mackenbach JP, Valverde JR, Artnik B, et al. Trends in health inequalities in 27 European countries. Proc Natl Acad Sci U S A 2018;115:6440-5.

5 Strand BH, Grøholt E-K, Steingrímsdóttir OA, et al. Educational inequalities in mortality over four decades in Norway: prospective study of middle aged men and women followed for cause specific mortality, 1960-2000. BMJ 2010;340:c654.

6 Link BG, Phelan J. Social conditions as fundamental causes of disease. J Health Soc Behav 1995;Spec No:80-94. 
7 Moor I, Spallek J, Richter M. Explaining socioeconomic inequalities in self-rated health: a systematic review of the relative contribution of material, psychosocial and behavioural factors. J Epidemiol Community Health 2017;71:565-75.

8 Klokgieters SS, Kok AA, Visser M. Socioeconomic inequalities in physical performance across birth cohorts: has the explanatory role of psychological, social, and behavioural factors changed? European Journal of Public Health 2020.

9 Lee C-won, Kahende J. Factors associated with successful smoking cessation in the United States, 2000. Am J Public Health 2007;97:1503-9.

10 Raho E, van Oostrom SH, Visser M, et al. Generation shifts in smoking over 20 years in two Dutch population-based cohorts aged 20-100 years. BMC Public Health 2015;15:142.

11 Mackenbach JP, Kulhánová I, Artnik B, et al. Changes in mortality inequalities over two decades: register based study of European countries. BMJ 2016;353:i1732.

12 Ellwardt L, van Tilburg T, Aartsen M, et al. Personal networks and mortality risk in older adults: a twenty-year longitudinal study. PLoS One 2015;10:e0116731.

13 de Graaf PM, Kalmijn M. Change and stability in the social determinants of divorce: a comparison of marriage cohorts in the Netherlands. Eur Sociol Rev 2006;22:561-72.

14 Suanet B, van Tilburg TG, Broese van Groenou MI. Nonkin in older adults' personal networks: more important among later cohorts? J Gerontol B Psychol Sci Soc Sci 2013;68:633-43.

15 Suanet B, Aartsen MJ, Hoogendijk EO, et al. The social SupportHealth link unraveled: pathways linking social support to functional capacity in later life. J Aging Health 2020;32:616-26.

16 Drewelies J, Agrigoroaei S, Lachman ME, et al. Age variations in cohort differences in the United States: older adults report fewer constraints nowadays than those 18 years ago, but mastery beliefs are diminished among younger adults. Dev Psychol 2018;54:1408-25.

17 Brailean A, Comijs HC, Aartsen MJ, et al. Late-Life depression symptom dimensions and cognitive functioning in the longitudinal aging study Amsterdam (LasA). J Affect Disord 2016;201:171-8.

18 Matthews KA, Gallo LC. Psychological perspectives on pathways linking socioeconomic status and physical health. Annu Rev Psychol 2011;62:501-30.

19 Singh-Manoux A, Ferrie JE, Lynch JW, et al. The role of cognitive ability (intelligence) in explaining the association between socioeconomic position and health: evidence from the Whitehall II prospective cohort study. Am J Epidemiol 2005;161:831-9.

20 Chapman BP, Fiscella K, Kawachi I, et al. Personality, socioeconomic status, and all-cause mortality in the United States. Am J Epidemiol 2010;171:83-92.

21 Huisman M, Poppelaars J, van der Horst M, et al. Cohort profile: the longitudinal aging study Amsterdam. Int J Epidemiol 2011;40:868-76.

22 Picavet HSJ, Blokstra A, Spijkerman AMW, et al. Cohort profile update: the Doetinchem cohort study 1987-2017: lifestyle, health and chronic diseases in a life course and ageing perspective. Int $J$ Epidemiol 2017;46:1751-1751g.

23 Wood AM, Kaptoge S, Butterworth AS, et al. Risk thresholds for alcohol consumption: combined analysis of individual-participant data for 599912 current drinkers in 83 prospective studies. Lancet 2018;391:1513-23.
24 Pols MA, Peeters PH, Ocké MC. Estimation of reproducibility and relative validity of the questions included in the EPIC physical activity questionnaire. Int J Epidemiol 1997;26 Suppl 1:S181-9.

25 Ainsworth BE, Haskell WL, Herrmann SD, et al. 2011 compendium of physical activities: a second update of codes and Met values. Med Sci Sports Exerc 2011;43:1575-81.

26 Pearlin LI, Schooler C. The structure of coping. J Health Soc Behav 1978;19:2-21.

27 Sherer M, Maddux JE, Mercandante B, et al. The self-efficacy scale: construction and validation. Psychol Rep 1982;51:663-71.

28 Barelds DPH, Luteijn F. Measuring personality: a comparison of three personality questionnaires in the Netherlands. Pers Individ Dif 2002;33:499-510.

29 Cohen S, Doyle WJ, Skoner DP, et al. Social ties and susceptibility to the common cold. JAMA 1997;277:1940-4.

30 Burgos Ochoa L, Rijnhart JJ, Penninx BW. Performance of methods to conduct mediation analysis with time-to-event outcomes. Stat Neerl 2020;74:72-91.

31 Rijnhart JJM, Twisk JWR, Eekhout I, et al. Comparison of logisticregression based methods for simple mediation analysis with a dichotomous outcome variable. BMC Med Res Methodol 2019;19:19.

32 Valeri L, Vanderweele TJ. Mediation analysis allowing for exposuremediator interactions and causal interpretation: theoretical assumptions and implementation with SAS and SPSS macros. Psychol Methods 2013:18:137-50.

33 Mackinnon DP, Lockwood CM, Williams J. Confidence limits for the indirect effect: distribution of the product and resampling methods. Multivariate Behav Res 2004;39:99-128.

34 Carrigan MH, Ham LS, Thomas SE, et al. Alcohol outcome expectancies and drinking to cope with social situations. Addict Behav 2008;33:1162-6.

35 Wang Y-P, Andrade LH. Epidemiology of alcohol and drug use in the elderly. Curr Opin Psychiatry 2013;26:343-8.

36 Saint-Maurice PF, Coughlan D, Kelly SP, et al. Association of leisuretime physical activity across the adult life course with all-cause and cause-specific mortality. JAMA Netw Open 2019;2:e190355.

37 Braam AW, Beekman AT, Knipscheer CP, et al. Religious denomination and depression in older Dutch citizens: patterns and models. J Aging Health 1998;10:483-503.

38 Kunst AE, Looman CW, Mackenbach JP. Determinants of regional differences in lung cancer mortality in the Netherlands. Soc Sci Med 1993;37:623-31.

39 Janssen F, Spriensma A. The contribution of smoking to regional mortality differences in the Netherlands. Demogr Res 2012;27:233-60.

40 BRONS LL. Indirect measurement of regional culture in the Netherlands. Tijdschr Econ Soc Geogr 2006;97:547-66.

41 Bambra C. Health inequalities and welfare state regimes: theoretical insights on a public health 'puzzle'. J Epidemiol Community Health 2011;65:740-5.

42 Mood C. Logistic Regression: Why We Cannot Do What We Think We Can Do, and What We Can Do About It. Eur Sociol Rev 2010;26:67-82.

43 Groffen DAI, Bosma H, Tan FES, et al. Material vs. psychosocial explanations of old-age educational differences in physical and mental functioning. Eur J Public Health 2012;22:587-92. 